\title{
Kılavuzlu Baraj Gölü'nde Landsat Termal Görüntüleri ile Su Yüzey Sıcaklığı Arasındaki İlişkinin Değerlendirilmesi
}

\section{Muhterem KÜÇÜKÖNDER ${ }^{* 1}$}

${ }^{1}$ Kahramanmaraș Sütçü İmam Üniversitesi, Fen Edebiyat Fakültesi, Coğrafya Bölümü, Kahramanmaraş, Türkiye

Anahtar Kelimeler:

Su yüzey sıcaklığ

Landsat TIRS

Kılavuzlu Baraj Gölü

Kahramanmaraş
ÖZ

Antropojenik ve/veya doğal faktörlerdeki değişimlere duyarlı olan kıta içi su kütlelerinde gözlenen önemli parametrelerden biri su yüzey sicaklıklarıdır. Sürdürülebilir su kaynakları yönetimi ve ekolojik fonksiyonların korunması amacıyla düzenli yersel ölçümlerinin yapılamadığı birçok çalışmada su yüzeyi sıcaklıklarının izlenmesinde uydu tabanlı termal veriler yaygın olarak kullanılmaktadır. Ülkemizde 1000 'e yakın doğal ve yapay kıta içi su kütlesi bulunmaktadır. Bunlardan biri olan Kılavuzlu Baraj Gölü (Kahramanmaraş), su yüzey sıcaklıkları 2018 yılının üç döneminde yerinde ölçümlerle ölçülmüștür. Bu çalıșmanın amacı, Landsat 8 termal görüntüleri ile algılanan su yüzey sıcaklıkları ile yerinde ölçümler arasındaki tutarlılığın değerlendirilmesidir. Yerinde ölçüm sonuçlarına göre, en düşük ortalama su yüzey sıcaklık değerleri $\left(14,38^{\circ} \mathrm{C}\right)$ Nisan ayında ve en yüksek ortalama su yüzey sicaklık değerleri $\left(21,45^{\circ} \mathrm{C}\right)$ Ağustos ayında ölçülmüştür. Ordinary Least Square (OLS) sonuçlarına göre, yerinde ve termal sıcaklık modeli arasındaki uyum derecesi 0,65 , ortalama karekök hatası 2,55 derece ve standart hata 1,54 derecedir. Landsat termal görüntülerinden Kasım ayında elde edilen su yüzey sıcaklık değerleri yer ölçümlerinden daha düşüktür. Modelde ise Nisan ayı sıcaklıklarının standart hata değerleri daha yüksektir. Geliştirilen modelin Kılavuzlu baraj gölünde tüm dönemlerdeki sınırlı yersel veri nedeniyle uygulanabilirliği düşük olmasına karşın bölge için su yüzeyi sıcaklıklarının izlenmesinde önemli bir potansiyele sahip olduğunu göstermiştir.

\section{Assessment of The Interrelation Between Water Surface Temperature and Landsat Thermal Images in Kilavuzlu Reservoir}

\author{
Keywords: \\ Water surface \\ temperature \\ Landsat TIRS \\ Kılavuzlu Reservoir \\ Kahramanmaraş
}

\begin{abstract}
Water surface temperature is one of the important parameters observed in inland waters that are sensitive to changes in anthropogenic and/or natural factors. To manage sustainable water resources management and protection of ecological functions, satellite-based thermal data are widely used in monitoring water surface temperatures in many studies where regular in-situ measurements cannot be measure. Our country has approximately 1000 natural and artificial inland water bodies. Kılavuzlu Dam Lake (Kahramanmaraş) that one of them, the water temperature was obtained by in-situ measurements in three periods of 2018. This study aims to assess the consistency between the water surface temperatures sensed with the Landsat 8 thermal images and in-situ data. According to the in-situ measurement results, while the lowest mean water surface temperature values $\left(14,38^{\circ} \mathrm{C}\right)$ were measured in April, the highest mean water surface temperature values $\left(21,45^{\circ} \mathrm{C}\right)$ were measured in August. Ordinary Least Square (OLS) results shows that, the degree of fit between the in-situ and thermal temperature model was 0,65 , the root mean square error was 2,55 degrees, and the standard error was 1,54 degrees. The water temperature values obtained in Landsat thermal images in November are lower than the ground measurements. While, in the model, the standard error values of the temperatures in April are higher. Although the applicability of the developed model in the Kilavuzlu Reservoir is low due to limited in-situ data in all periods, it has shown that it has significant potential in monitoring water surface temperatures for the region.
\end{abstract}




\section{GíRiş}

Su kütleleri, ekolojik dengenin korunması ve fiziksel, kimyasal ve biyolojik süreçlerin sürdürülmesi süreçlerinde sıcaklık değişimlerine oldukça hassas yapılardır (Fakıoğlu vd., 2011; Zhang vd., 2019). Antropojenik ve/veya doğal nedenlerden kaynaklanabilen su kütlelerinde sıcaklık trendleri iklim değişimi, hidrolojik modelleme ve su kalitesi ile ilişkili biyosfer sağlığının değerlendirilmesinde önemli bir parametredir (Bonansea vd., 2021). Bu nedenle dünyada ve ülkemizde kıta içi ve açık suların sıcaklık trendlerinin izlenmesi zaman ve maliyet gibi sınırlılıkları barındıran konvansiyonel yöntemlerin yanı sıra zamansal ve alansal izleme kabiliyeti yüksek termal algılayıcılarla gerçekleştirilmektedir (Lamaro vd., 2013; Simon vd., 2014; Ding \& Elmore, 2015). Son yıllarda Landsat 8 termal görüntüleri kıta içi sularda yüzey sıcaklığının belirlenmesi yaygın olarak kullanılmaktadır (Ptak vd., 2017; Jang \& Park, 2019; Sharaf vd., 2019; Bonansea vd., 2021).

Ülkemizde de çeşitli göl ve sulak alanlarda, Umurbey Deltası (Çakaroz vd., 2020), Sarıkum Gölü (Topuz \& Karabulut, 2018), Aslantaş barajı (Gülci vd., 2019), Mogan gölü (Özçalık vd., 2020), Burdur Gölü (Sabuncu, 2020) Landsat görüntüleri ile alansal ve zamansal kıyı çizgisi değişimlerini ve Abant Gölü su kalite parametrelerini belirlemek (Karakaya vd., 2011) üzere yapılan çalışmalar bulunmaktadır. Landsat görüntüleri yanı sıra yüksek çözünürlüklü Sentinel 2 (Peker, 2019), Worldview 3 (Tuzcu, 2019) verileri kullanılarak göl ve sulak alanların alansal değişimi izleme çalışmaları gerçekleştirilmektedir.
Kıta içi su kütlelerinin sıcaklıklarının uydu tabanlı verileri ile izlenmesi üzerine ise ülkemizde oldukça sınırlı sayıda çalışma bulunmaktadır (Şener, 2016).

Ceyhan havzasında Kahramanmaraş sinırları içerisinde çeşitli amaçlarla kurulmuş ve faaliyet gösteren 20'den fazla baraj ve gölet bulunmaktadır. Bölgede yer alan akarsu ve barajlarda su kalitesini belirlemeye yönelik yersel örnekleme yöntemine dayanan çeşitli çalışmalar gerçekleştirilmiştir (Kara \& Çömlekçioğlu, 2004; Tanrıverdi vd., 2010; HKEPHCH, 2010; Bozkurt, 2016; K-ÇDR, 2016; Küçükönder vd., 2022). Seçilen çalışma alanında uzaktan algılama temelli su yüzey sıcaklıklarının belirlenmesine yönelik bir çalışma bulunmamaktadır. Bölgede evsel kullanım, tarımsal sulama, su ürünleri yetiştiriciliği, elektrik üretimi gibi ön plana çlkan baraj ve göletlerin kullanım nitelikleri ile su hacminin ve su kalitesinin izlenmesi ekonomik ve ekolojik olarak oldukça önemlidir. Kafes tipi balık yetiştiriciliği amacıyla da kullanılan Kılavuzlu baraj gölünde su sıcaklığı değişimi üretim niteliğini etkileyecek önemli parametrelerden biridir (Dikel, 2009). Bu çalışmanın amacı tatlı su rezervlerinin kalitesinin izlenmesinde önemli bir parametre olan sicaklık değerlerinin Kılavuzlu baraj gölünde 2018 yll mevsimsel değișiminin Landsat 8 Termal Kızılötesi Algılayıcı (TIRS) görüntüleri kullanılarak belirlenmesi ve tutarlılıklarının yersel ölçümler ile karşılaştırılmasıdır. Yersel ölçülen sıcaklıklar ile ısıl görüntülerden elde edilen sıcaklıklar arasında validasyon En Küçük Kareler (OLS) regresyon yöntemi kullanılarak hesaplanmıştır.

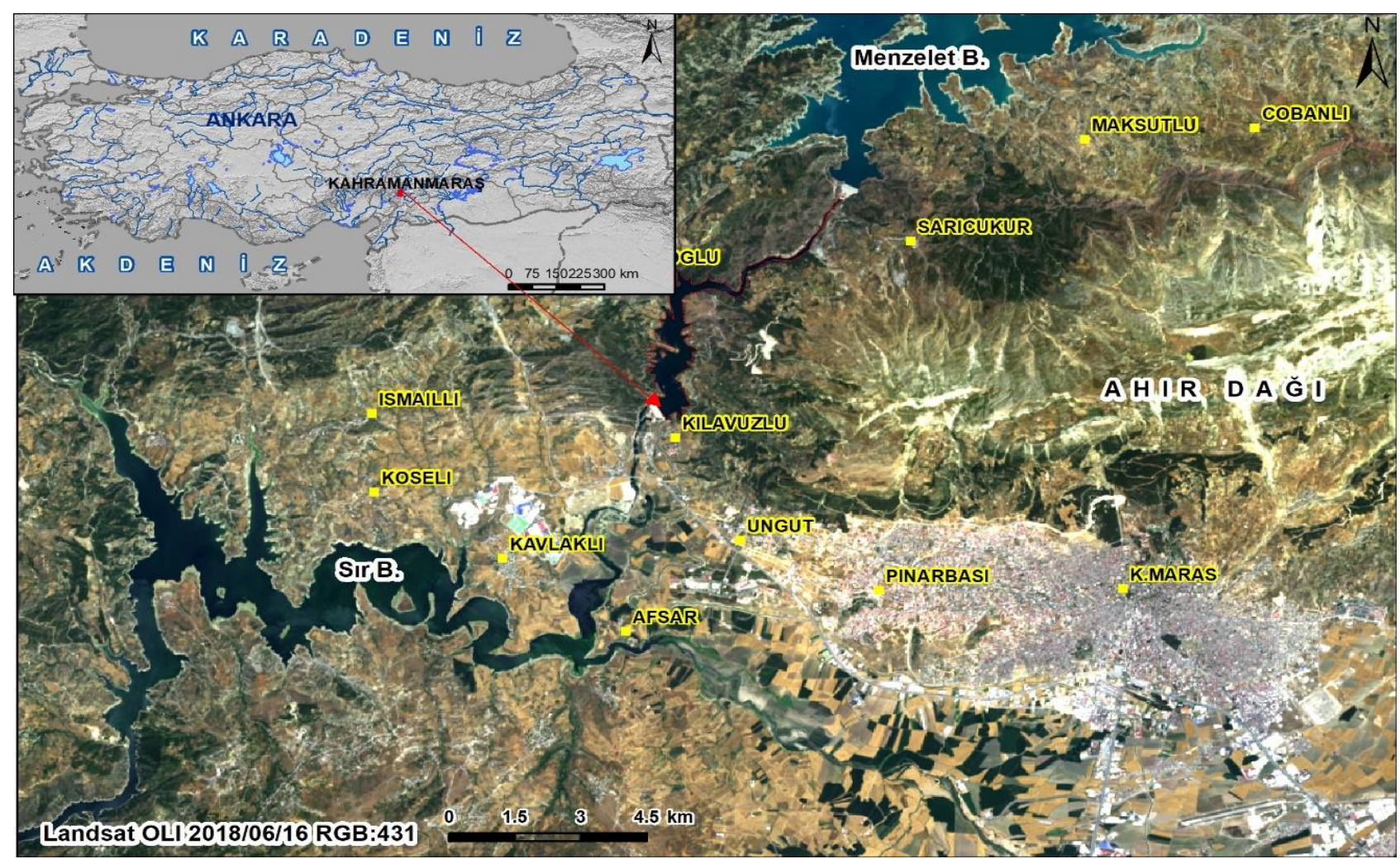

Şekil 1. Çalışma alanı yer bulduru haritası 


\section{YÖNTEM}

\section{1. Çalışma Alanı}

Ceyhan havzası içerisinde yer alan Kılavuzlu Baraj Gölü Kahramanmaraş kentinin $18 \mathrm{~km}$ kuzeybatısında Ceyhan Nehri üzerinde 2014 yılında işletmeye alınmıștır (Şekil 1). Baraj, tarımsal sulama, enerji üretimi, su ürünleri yetiştiriciliği ve su sporları amacıyla kullanılmaktadır. Kuzeyinde Menzelet barajı ve güneyinde Sır barajı bulunmaktadır (Şekil 1). Gövde tipi zonlu toprak dolgu olan barajın; gövde

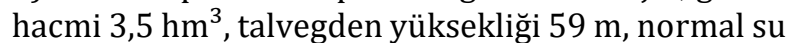
kotunda göl hacmi $69 \mathrm{hm}^{3}$ ve normal su kotunda göl alanı $3 \mathrm{~km}^{2}$ dir (Turgut \& Küçükönder, 2016). Kılavuzlu barajı alt havzası 48,8 $\mathrm{km}^{2}$ lik bir yüzey drenaj alanına sahiptir ve göl alanı yüzey drenajı mevsimlik akarsular ile sağlamaktadır (Küçükönder vd., 2022).

Meteoroloji Genel Müdürlüğü (MGM) 19912020 yılları arası Kahramanmaraş meteoroloji istasyonu istatistiklerine göre bu çalışmada sıcaklık ölçüm dönemlerini içeren nisan, ağustos ve kasım ayları ortalama sıcaklık değerleri sırasıyla $15,6{ }^{\circ} \mathrm{C}$, $29,2^{\circ} \mathrm{C}$ ve $11,8^{\circ} \mathrm{C}^{\prime} \operatorname{dir}(\mathrm{MGM}, 2021)$. Akdeniz ikliminin gözlendiği çalışma alanında yıllık toplam yağıș miktarı 750,9 mm ve yağışlar çoğunlukla kış ve ilkbahar mevsimlerinde düş̧mektedir (Şekil 2).

2018 yılı Avrupa Çevre Ajansı tarafından belirlenen Arazi Örtüsü/Kullanımı Sınıflandırması CORINE (Coordination of Information on the Environment-Çevresel Bilginin Koordinasyonu) verilerine göre kırsal yerleşim, karışık tarım alanları ve orman alanları bulunmaktadır. 1990 ve 2018 yılları seviye 3-4 sınıfları havza sınırı içerisinde karşılaştırılmıştır (Şekil 3). Geniş yapraklı ormanlar, inşaat sahaları, sürekli sulanan alanlar ve çılak kayalıklar 1990 yılı sınıflamasında yer alırken 2018 yılı sonuçlarında bu arazi kullanım/örtü alanlarının yer almadığı görülmektedir. Barajda kafes tipi su ürünleri yetiştiriciliği yapılmaktadır. CORINE değişim bilgilerine göre 2000 yllı sonrası havzada bir maden sahası (25 ha) yanı sıra küçük ölçekli besi tesisleri (21 ha) faaliyet göstermektedir (K-ÇDR, 2016). Doğal bitki örtüsü ile karışık tarım alanları, doğal çayırlıklar, su kütleleri ve sulanan karışık tarım alanları sırasıyla 395 ha, 720 ha, 41 ha ve 371 ha artış göstermiştir. Sulanmayan karışık tarım alanları, karışık ormanlar, iğne yapraklı ormanlar ve seyrek bitki alanları ise sırasıyla 1023 ha, 169 ha, 35 ha ve 34 ha azalmıştır (URL-2). Arazi örtüsünde belirgin değişimler barajın yapımı ile sulanan tarım alanlarının artışı ve farklı nitelikteki orman alanlarının ise bitki değişim alanlarına ve doğal çayırlık sınıflarına geçişi olarak görülmektedir.

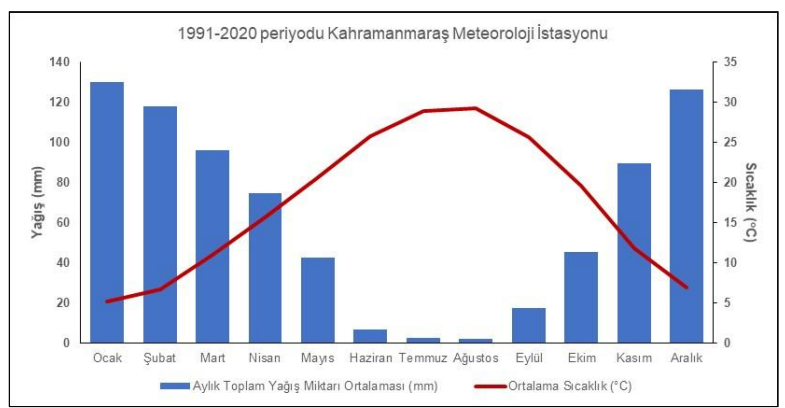

Şekil 2. Kahramanmaraş meteoroloji istasyonu 1991-2020 periyodu aylık toplam yağış $(\mathrm{mm})$ ve aylık ortalama sıcaklık $\left({ }^{\circ} \mathrm{C}\right)$ değerleri

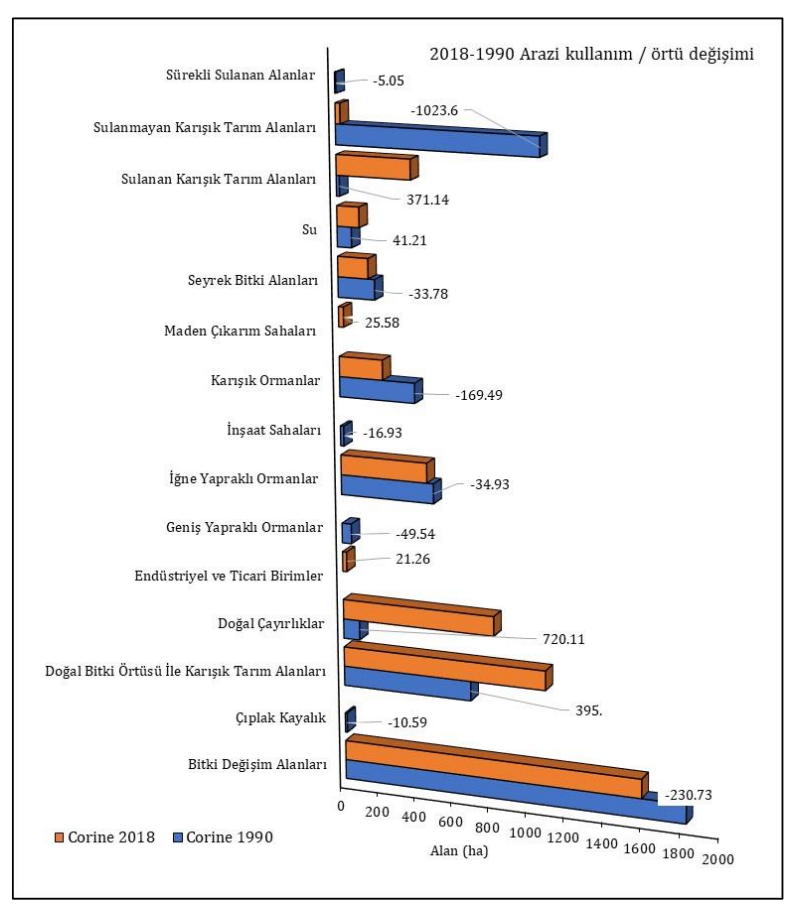

Şekil 3. Kılavuzlu havzası 1990-2018 yılları arası CORINE seviye3-4 arazi kullanım/örtü değişimleri

\subsection{Yersel Veriler}

Hava koşullarının uygun olduğu bulutsuz ve rüzgarsız günler ve aynı zamanda uydu geçiş günleri ile eş zamanlılık yakalanmaya çalışılarak saha çalışmaları planlanmıştır (Tablo 1). 25 Nisan, 3 Ağustos ve 9 Kasım 2018 tarihlerinde su yüzey sıcaklıkları ölçümleri WTW 330i cihazı ile gerçekleştirilmiştir. Örnekleme noktaları, baraj gölü kıyı kesimlerinde potansiyel bir yeraltı ve yüzey su karışım etkisinin ve sığ bölgelerde taban yansımasının en aza indirilmesi amacıyla 2014 öncesi topografya haritasında su kotunun $15 \mathrm{~m}$ ile 40 $m$ arasında değiştiği alanlarda konumlandırılmıştır (Şekil 4a). Yersel sıcaklık ölçümleri çalışma alanında Landsat 8 görüntüleme saati olan 08:08 dikkate alınarak en fazla 2 saat fark oluşacak şekilde alınmıştır (Şekil 4b ve c). 


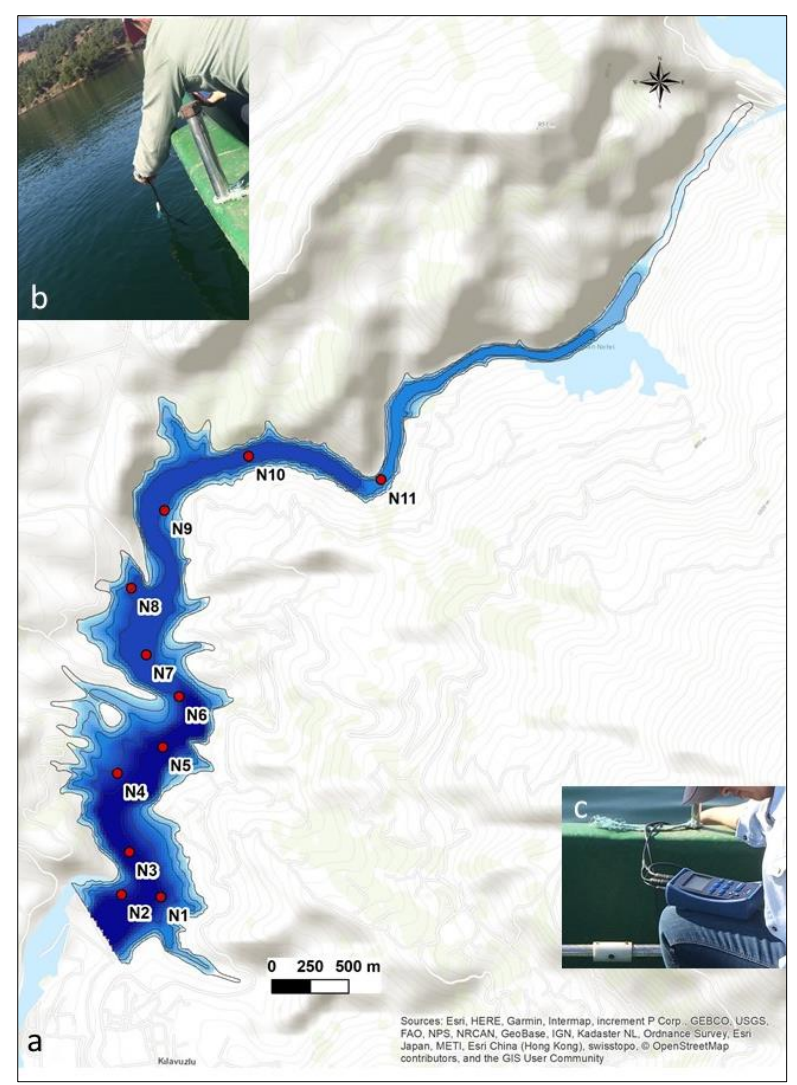

Şekil 4. Baraj gölü veri toplama noktaları ve ölçüm çalışmaları

Tablo 1. Yersel sıcaklık ölçümleri sırasında gözlemlenen hava sıcaklıkları

\begin{tabular}{lcc}
\hline $\mathbf{2 0 1 8}$ & Sicaklık ( $\left.^{\circ} \mathbf{C}\right)$ & Hava koşulları \\
\hline 25 Nisan & 21 & Bulutsuz \\
03 Ağustos & 29 & Bulutsuz \\
9 Kasım & 8 & Parçalı bulutlu \\
\hline
\end{tabular}

\subsection{Termal Görüntüler}

Baraj göl yüzeyinin yersel ölçüm dönemlerinde sıcaklık değerleri $100 \mathrm{~m}$ mekânsal çözünürlüklü Landsat 8 Termal Kızılötesi Algllayıcı (TIRS) görüntülerinden hesaplanmıştır. 174/34 yörünge ve sira numarası ile USGS Earth Resources Observation and Science (URL-1) adresinden level 1 geoTIFF formatında temin edilmiştir. MGM hava tahmin raporları kontrol edilerek planlanan saha çalışmalarında hava koşulları nedeniyle ilkbahar ve sonbahar görüntüleri yersel ölçümler ile görüntü tarihlerinde - 4 ve +2 gün farklılık meydana gelmiştir (Tablo 2).

Tablo 2. Görüntü ve örnekleme günleri farkları

\begin{tabular}{ccc}
\hline Ölçüm tarihi & Görüntü tarihi & Fark \\
\hline 25 Nisan & 29 Nisan & 4 gün önce \\
03 Ağustos & 03 Ağustos & - \\
9 Kasım & 7 Kasım & 2 gün sonra \\
\hline
\end{tabular}

\subsubsection{Veri İşleme}

Landsat TIRS Level 1 verileri dijital sayıları (DN) radyometrik yeniden ölçeklendirme faktörleri kullanılarak atmosfer üstü (TOA) radyans değerlerine ve termal sabit parametreleri kullanılarak (K1 = 774,8853 ve K2 = 1321,0789) TOA parlaklık sıcaklık değerlerine dönüştürülmüştür. Tüm dönüşüm işlemlerinde Landsat 8 Bilimsel Veri Kullanıcıları kılavuzunda (USGS, 2019) belirtilen algoritmalar dikkate alınmıştır. Atmosferik düzeltmeler Tek Kanal (Single-Channel: SC) algoritması (Lamaro vd., 2013; Jiménez-Muñoz vd., 2014) ile gerçekleştirilerek su yüzey sıcaklığı hesaplanmıştır. Yersel ölçümler ile uyumlu olması için birim dönüşümü yapılarak Kelvin (K) sıcaklık değerleri Santigrat (C) dereceye çevrilmiştir.

$\mathrm{Su}$ seviyesinin en yüksek olduğu 29 Nisan Landsat optik bandları kullanılarak oluşturulan Normalize Fark Su İndisi (Xu, 2006) ile su yüzey alanı tespit edilmiş ve tüm termal görüntülerde kara alanları sıcaklık görüntülerinde maskelenmiştir.

\section{4. İstatistiksel Analizler}

Yersel ölçülen sıcaklıklar ile ısıl görüntülerden elde edilen sıcaklıklar En Küçük Kareler (OLS) regresyon yöntemi validasyon değerleri hesaplanmıştır. Küçük bir örnekleme kümesi (yersel 33 ölçüm) ile çalışılması nedeniyle çalışmada OLS yöntemi tercih edilmiştir. Yersel ve uydu sıcaklık ilişkisi ölçüm arasında model uyumluluk derecesi $\left(\mathrm{R}^{2}\right)$, ortalama karekök hatası (RMSE) ve Akaike bilgi kriter değeri (AIC) hesaplanmıştır (Mitchell, 2005).

\section{BULGULAR}

Kılavuzlu baraj gölünde Nisan, Ağustos ve Kasım 2018 tarihlerinde yersel ölçümler toplanmış ve Landsat TIRS görüntülerinden aynı dönem su yüzey sıcaklıkları hesaplanmıștır. Baraj gölünün mevsimlik alansal değişimi dikkate alınarak tamamı için değil ölçüm konumları ile çakışan piksel sıcaklık değerleri istatistiksel hesaplamalarda kullanılmıştır. Nisan, Ağustos ve Kasım tarihlerinde yerinde alınan sıcaklık değerleri ortalamaları ve standart sapma değerleri sırasıyla $14,38 \pm 0,18^{\circ} \mathrm{C}, 21,45 \pm 0,58^{\circ} \mathrm{C}$ ve $16,42 \pm 0,07^{\circ} \mathrm{C}$ olarak hesaplanmıştır (Tablo 3 ). 
Tablo 3. Yersel (Nx örneklem noktaları, Şekil 4) ve uydu sıcaklık ölçüm değerleri

\begin{tabular}{|c|c|c|c|c|c|c|c|c|c|c|c|c|}
\hline & & N1 & N2 & N3 & N4 & N5 & N6 & N7 & N8 & N9 & N10 & N11 \\
\hline \multirow{2}{*}{ 胥 } & \multirow{2}{*}{ 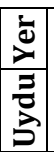 } & 14,3 & 14,5 & 14,4 & 14,1 & 14,5 & 14,5 & 14,2 & 14,7 & 14,5 & 14,1 & 14,4 \\
\hline & & 16,8 & 17,8 & 16,9 & 16,9 & 16,5 & 17,6 & 16,6 & 18,2 & 17,5 & 18 & 18,4 \\
\hline \multirow{2}{*}{ 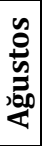 } & 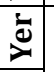 & 21,5 & 21,2 & 21,6 & 21,8 & 21,8 & 21,9 & 21,8 & 22,1 & 21,5 & 20,7 & 20,0 \\
\hline & 胥 & 22,9 & 23,6 & 23,0 & 22,8 & 22,7 & 24,8 & 23,8 & 23,6 & 23,3 & 23,4 & 26,1 \\
\hline \multirow{2}{*}{ 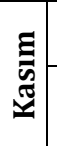 } & $\stackrel{\grave{d}}{\grave{\lambda}}$ & 16,4 & 16,5 & 16,4 & 16,4 & 16,3 & 16,4 & 16,5 & 16,5 & 16,5 & 16,4 & 16,3 \\
\hline & 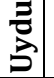 & 14,4 & 14,6 & 14,5 & 14,4 & 14,5 & 14,6 & 14,6 & 14,8 & 14,8 & 14,3 & 14,4 \\
\hline
\end{tabular}

Bölgenin Akdeniz iklimini ile ilişkili olarak sıcaklık trendleri ile uyumlu olarak baraj gölü en yüksek su sıcaklık değerleri ağustos ayında ölçülmektedir. Su yüzey sıcaklık görüntüsünde ise $17,38 \pm 0,64^{\circ} \mathrm{C}, \quad 23,63 \pm 0,95^{\circ} \mathrm{C}$ ve $14,53 \pm 0,15^{\circ} \mathrm{C}$ sıcaklık değerleri ortalamaları ve standart sapma değerleri sırasıyla Nisan (Şekil 5), Ağustos (Şekil 6) ve Kasım (Şekil 7) tarihleri için hesaplanmıștır (Şekil 8).

OLS modeli uyumluluk derecesi 0,65 ( $\left.\mathrm{R}^{2}\right)$ ve AIC 137,9 olarak hesaplanmıştır. Toplam örneklem kümesinde RMSE 2,55 derece iken standart hata 1,54 derecedir. Göllerde yapılan çeşitli çalışmaların sonuçları elde edilen değerlerin Literatürde Landsat TM TIR ile Arreo Gölünde (İspanya) RMSE $4,5^{\circ} \mathrm{C}$ (Rodríguez vd., 2014) Bariousses ve Bimont rezervuarları (Fransa) RMSE $1-2,4^{\circ} \mathrm{C}$ (Simon vd., 2014) validasyon değerleri tespit edilmiştir. Abant ve Yenicaaga göllerinde geliştirdikleri Çoklu Doğrusal Regresyon modelinde sıcaklık için sırasıyla 0,998 ve $0,528\left(\mathrm{R}^{2}\right)$ uyumluluk hesaplamışlardır (Karakaya vd., 2011).

OLS standart sapma barajın daraldığı kuzey N10 ve N11 örnekleme noktalarında (yeşil noktalar) daha fazla olmak üzere kurulan modelde nisan dönemi değerleri termal görüntülerden daha düşük sıcak olarak belirlenmektedir (Şekil 6). Ağustos dönemi aynı tarihli yersel veri ve termal dönüşümler, modelde daha yüksek uyumluluk (sarı noktalar) göstermektedir (Şekil 7).

Termal görüntülerde sıcaklık değerleri Nisan ve Ağustos verileri daha yüksek iken Kasım değerleri daha düşüktür. Kasım dönemi görüntüsünün yer ölçüm tarihinden iki gün sonra gerçekleşmesi ve hava sıcaklıklarının azaldığı bir mevsim içinde olması bu durumun etken parametreleri arasında olabileceği düşünülmektedir. Literatürde bu ilişkinin hesaplanabilmesi için günlük su sıcaklık ölçümlerinin kesintisiz olması (Ding \& Elmore, 2015) aynı zamanda termal görüntülerin atmosferik düzeltilmesinde saatlik atmosferik sıcaklık gözlemlerinin modele entegre edilmesi (Bonansea vd., 2020) önerilmektedir. Hava koşullarının su yüzey sıcaklıklarında etkinliğinin karşılaştırması bu çalışmada yersel ölçümlerin kısıtlı olması nedeniyle gerçekleştirilememiştir.

Su sıcaklık görüntülerinde kara-su maskeleme işlemi Nisan görüntüsü esas alınarak gerçekleștirildiği için kıyı alanlarında su seviyesinin değișimi izlenebilmektedir. Kasım en düșük hava ve su sıcaklığı etmenleri ile en yüksek su seviyesi yakalanırken, Ağustos dönemi en yüksek hava ve su sıcaklığı etmenleri ile kıyı şeridinde su seviyesi düşen alanlar kırmızı $\left(>30^{\circ} \mathrm{C}\right)$ olarak görülmektedir.

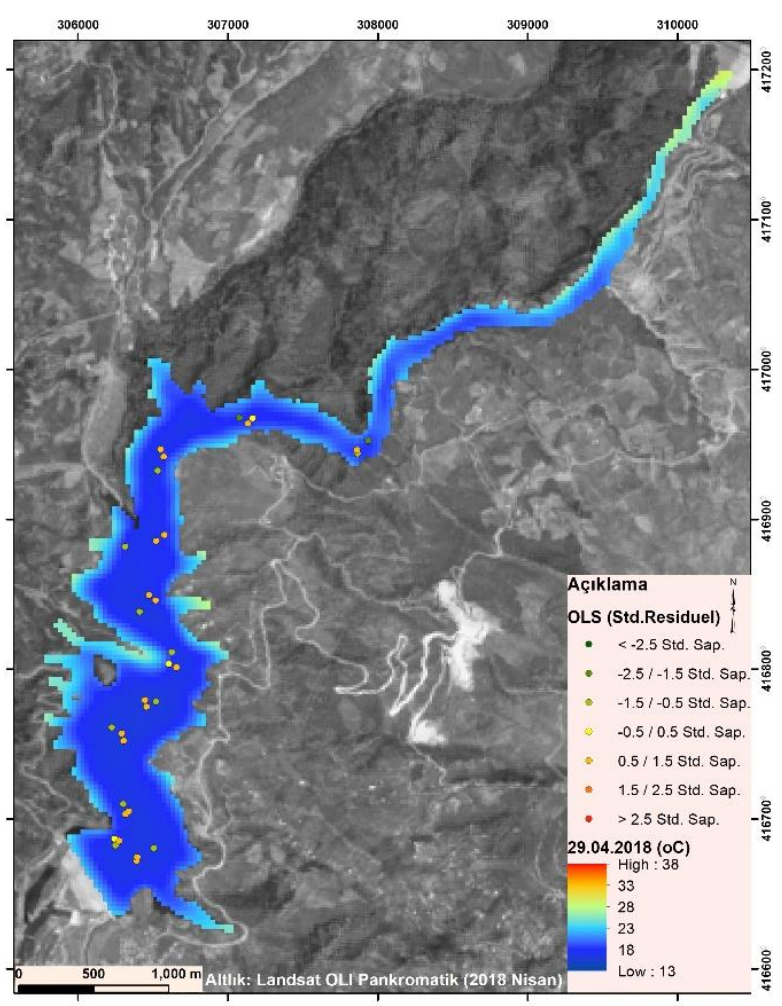

Şekil 5. 29 Nisan 2018 sicaklık görüntüsü ve örneklem noktaları hata oranları 


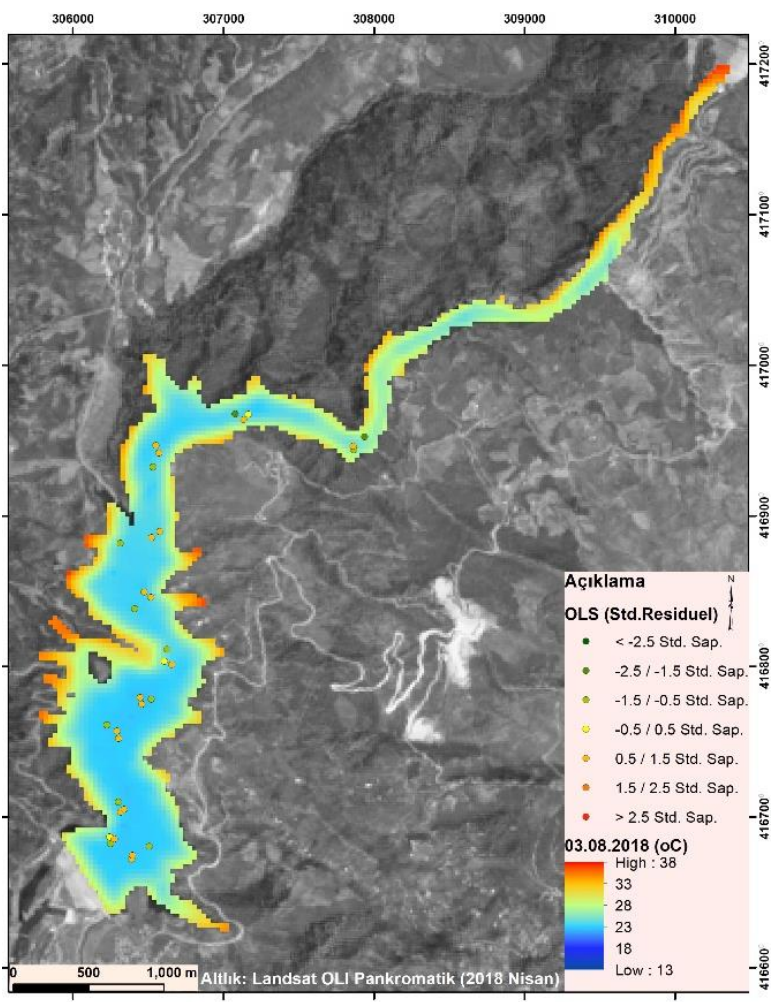

Şekil 6. 3 Ağustos 2018 sıcaklık görüntüsü ve örneklem noktaları hata oranları

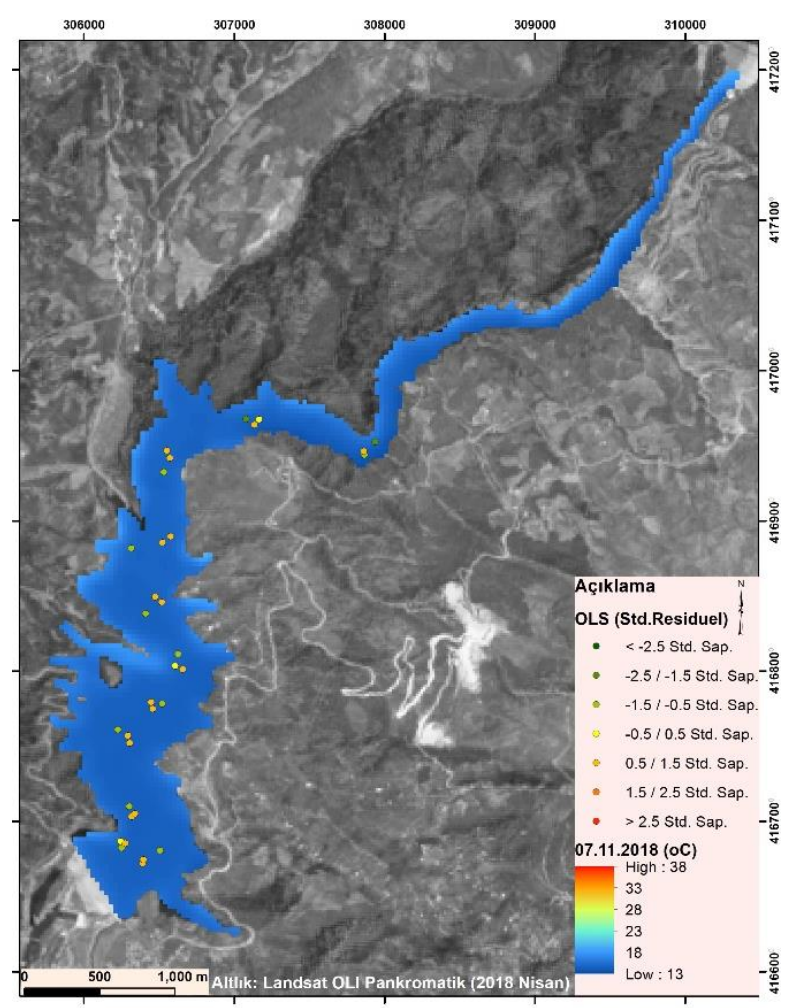

Şekil 7. 7 Kasım 2018 sicaklık görüntüsü ve örneklem noktaları hata oranları

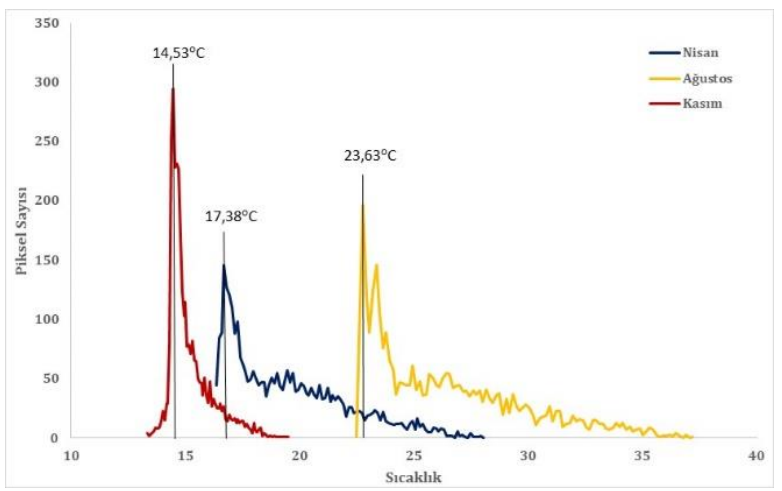

Şekil 8. Nisan, Ağustos ve Kasım su yüzey sıcaklık histogramları

\section{SONUÇLAR}

Bu çalışmada Kılavuzlu baraj gölünde Landsat 8 TIRS görüntüleri kullanılarak Nisan, Ağustos ve Kasım tarihlerinde su yüzey sıcaklıkları hesaplanmıştır. Yersel ölçümler ile hesaplanan termal görüntü su sıcaklıkları OLS yöntemi ile modellenmiștir. Yersel su ölçümleri ile nisan ve kasım dönemlerinde zamansal farklılıklar bulunmasına karşın model açıklayıcılığı \%65'dir. Çalışma alanı için geliştirilen modelin yersel verilerin kısıtlılığı nedeniyle tüm dönemlerde uygulanabilirliği düşük olmakla birlikte su yüzey sıcaklıklarının izlenmesinde önemli bir potansiyel taşıdığı görülmektedir.

Kılavuzlu baraj gölünde Bozkurt (2016) tarafından Ağustos dönemi $14,65^{\circ} \mathrm{C}$ olarak belirtilen sıcaklık ortalaması, 2018 yılı Ağustos ortalaması ile karşılaştırıldığında ortalama sıcaklığın arttığı görülmektedir. $\mathrm{Su}$ kütlelerinde sicaklık değişimlerinin bölgede izlenmesi değişim trendlerinin anlamlılı derecelerinin belirlenmesinde önemli olduğu görülmektedir.

Ülkemizden 100'den fazla doğal göl ve farklı işletme fonksiyonları ile kurulmuş 861 adet baraj bulunmaktadır. Kahramanmaraş il sınırları içinde ise planlama ve inşa aşamasında olanlar haricinde 8 adet baraj faaliyet göstermektedir. Sürdürülebilir su kaynakları yönetiminde ve ekolojik fonksiyonların korunması amacıyla su kütlelerinde uzaktan algılama temelli sıcaklık parametresinin izlenmesi konvansiyonel yöntemlere sağlıklı bir alternatif oluşturmaktadır. Bu nedenle uydu tabanlı gözlemler için görüntü düzeltme modellerinin geliştirilmesi ve iyileştirilmesi üzerine yapılan çalışmaların sayısı artırılmalıdır.

\section{Bilgilendirme/Teşekkür}

$\mathrm{Bu}$ çalışma Kahramanmaraş Sütçü İmam Üniversitesi Bilimsel Araştırma Projeleri Koordinasyon Birimi tarafindan 2018/1-22M proje numaralı "Kahramanmaraş Kılavuzlu Baraj Gölünde Su Kalitesinin İzlenmesi" konusu ile ilgili olup, ilgili birimce desteklenmiştir. Yersel ölçüm çalışmalarında yardımcı olan yüksek lisans öğrencisi Erkan Kalkan'a teşekkürlerimi sunarım. 


\section{Araştırmacıların katkı oranı beyan özeti}

Yazar makaleye \%100 oranında katkı sağlamış olduğunu beyan eder.

\section{Çıkar çatışması beyanı}

Makale yazarı herhangi bir çıkar çatışması olmadığını beyan eder.

\section{KAYNAKÇA}

Bonansea, M., Ferrero, S., Ferral, A., Ledesma, M., German, A., Carreño, J., Rodriguez, C. \& Pinotti, L. (2021). Assessing water surface temperature from Landsat imagery and its relationship with a nuclear power plant. Hydrological Sciences Journal, 66(1), 50-58.

Bozkurt, A. (2016). Zooplankton of Kilavuzlu Dam Lake (Kahramanmaraş) and the effect of cage fish farming on water quality and zooplankton fauna of the Dam Lake. Journal of Aquaculture Engineering and Fisheries Research, 2(3), 97108.

Çakaroz, D., Özelkan, E. \& Karaman, M. (2020). Sulak alanlarda uzaktan alglama ile belirlenen zamansal değişime kuraklığın etkisinin incelenmesi: Umurbey deltası (Çanakkale) örneği. Avrupa Bilim ve Teknoloji Dergisi, (20), 898-916.

Dikel, S. (2009). Su sıcaklığının balık yetiştiriciliğine etkisi. Alinteri Journal of Agriculture Science, 16(1), 42-49.

Ding, H., \& Elmore, A. J. (2015). Spatio-temporal patterns in water surface temperature from Landsat time series data in the Chesapeake Bay, USA. Remote Sensing of Environment, 168, 335348.

Fakıoğlu, Ö., Atamanalp, Ö. \& Demir, N. (2011). Baraj göllerinde toksik mavi-yesil algler. Ankara Üniversitesi Çevrebilimleri Dergisi, 3(2), 65-71.

Gülci, S., Gülci, N., \& Yüksel, K. (2019). Aslantaş Baraj Gölü ve çevresinin su yüzey alanı ve arazi örtüsü değişiminin Landsat uydu görüntüleri kullanılarak izlenmesi. Journal of the Institute of Science and Technology, 9(1), 100-110.

HKEPH-CH (2010). Havza Koruma Eylem Planlarının Hazırlanması-Ceyhan Havzası, TÜBİTAK MAM Çevre Enstitüsü, Gebze, Türkiye.

Jang, J. C., \& Park, K. (2019). High-resolution sea surface temperature retrieval from Landsat 8 OLI/TIRS data at coastal regions. Remote Sensing, 11(22), 2687.

Jiménez-Muñoz, J. C., Sobrino, J. A., Skoković, D., Mattar, C., \& Cristóbal, J. (2014). Land surface temperature retrieval methods from Landsat-8 thermal infrared sensor data. IEEE Geoscience and remote sensing letters, 11(10), 1840-1843.

Kara, C. \& Çömlekçioğlu, U. (2004). Karaçay (Kahramanmaraş)'ın kirliliğinin biyolojik ve fiziko-kimyasal parametrelerle incelenmesi. KSÜ Fen ve Mühendislik Dergisi, 7(1).
Karakaya, N., Evrendilek, F., Aslan, G., Güngor, K., \& Karakas, D. (2011). Monitoring of lake water quality along with trophic gradient using Landsat data. International Journal of Environmental Science and Technology, 8(4), $817-822$

K-ÇDR (Kahramanmaraş İli Çevre Durum Raporu), (2016). Çevresel Etki Değerlendirme Hizmetleri ve Çevre İzinleri Şube Müdürlüğü, Çevre ve Şehircilik İl Müdürlüğü, Kahramanmaraş Valiliği.

Küçükönder, M., Kalkan, E., Cırık, K. (2022). Kılavuzlu Baraj Gölü (Kahramanmaraş) Su Kalitesi ve Kanada Su Kalite İndeks Sınıfı, Osmaniye Korkut Ata Üniversitesi Fen Bilimleri Enstitüsü Dergisi, DOI: $10.47495 /$ okufbed.972211.

Mitchell, A. (2005). The ESRI Guide to GIS Analysis, Volume 2: Spatial measurements and statistics. ESRI Press, ISBN:1-58948-116-X.

Lamaro, A. A., Marinelarena, A., Torrusio, S. E., \& Sala, S. E. (2013). Water surface temperature estimation from Landsat 7 ETM+ thermal infrared data using the generalized singlechannel method: Case study of Embalse del Río Tercero (Córdoba, Argentina). Advances in Space Research, 51(3), 492-500.

Meteoroloji Genel Müdürlüğü Resmi İstatistikleri (MGM), https://www.mgm.gov.tr/veridegerlendirme/i l-ve-ilceler-istatistik.aspx?k=A\&m=K.MARAS Erişim Tarihi: 01 Ekim 2021.

Özçalık, H., Torun, A. T., \& Bilgilioğlu, S.S. (2020). Landsat uydu görüntüleri kullanılarak Mogan Gölü'nün su yüzeyi ve arazi örtü değișiminin belirlenmesi. Türkiye Uzaktan Algllama Dergisi, 2(2), 77-84.

Peker, E. A. (2019). Spatio-temporal changes of lake water extents in lakes region (Turkey) using remote sensing. Yüksek Lisans Tezi, Orta Doğu Teknik Üniversitesi, Ankara, 149s.

Ptak, M., Choiński, A., Piekarczyk, J., \& Pryłowski, T. (2017). Applying Landsat Satellite Thermal Images in the Analysis of Polish Lake Temperatures. Polish Journal of Environmental Studies, 26(5).

Rodríguez, Y. C., El Anjoumi, A., Gómez, J. D., Pérez, D. R., \& Rico, E. (2014). Using Landsat image time series to study a small water body in Northern Spain. Environmental Monitoring And Assessment, 186(6), 3511-3522.

Sabuncu, A. (2020). Burdur Gölü kıyı şeridindeki değişiminin uzaktan algılama ile haritalanması. Afyon Kocatepe Üniversitesi Fen ve Mühendislik Bilimleri Dergisi, 20(4), 623-633.

Sharaf, N., Fadel, A., Bresciani, M., Giardino, C., Lemaire, B. J., Slim, K., Faour, G. \& Vinçon-Leite, B. (2019). Lake surface temperature retrieval from Landsat- 8 and retrospective analysis in Karaoun Reservoir, Lebanon. Journal of Applied Remote Sensing, 13(4), 044505.

Simon, R. N., Tormos, T., \& Danis, P. A. (2014). Retrieving water surface temperature from 
archive LANDSAT thermal infrared data: Application of the mono-channel atmospheric correction algorithm over two freshwater reservoirs. International Journal of Applied Earth Observation and Geoinformation, 30, 247250.

Şener, E. (2016). Burdur Gölü Yüzey Suyu Sıcaklığl Mevsimsel Değişiminin Landsat 8 Uydu Görüntüleri Kullanılarak Belirlenmesi. Mühendislik Bilimleri ve Tasarım Dergisi, 4(2).

Tanrıverdi, Ç., Alp, A., Demirkıran, A.R. \& Üçkardeş, F. (2010). Assessment of surface water quality of the Ceyhan River basin, Turkey. Environmental Monitoring and Assessment, 167(1), 175-184.

Topuz, M., \& Karabulut, M. (2018). Sarıkum gölünde (Sinop) meydana gelen zamansal değişimlerin ve ekolojik etkilerinin incelenmesi. Journal of International Social Research, 11(60).

Turgut, A. \& Küçükönder, M. (2016). Kahramanmaraş İli Barajlarında Landsat 8 (OLI) kullanarak su kalitesinin izlenmesi. 6. Uzaktan Algılama-CBS Sempozyumu, Adana, Türkiye, 640-649.
Tuzcu, A. (2019). Akgöl Sulak Alanı'nın yüksek çözünürlüklü uydu görüntüleri ile incelenmesi. Yüksek Lisans Tezi, İstanbul Teknik Üniversitesi, İstanbul, 278s.

USGS, 2019. Landsat 8 data user's handbook [online]. https://www.usgs.gov/media/files/landsat-8data-users-handbook.

$\mathrm{Xu}, \mathrm{H}$. (2006). Modification of normalized difference water index (NDWI) to enhance open water features in remotely sensed imagery. International Journal of Remote Sensing, 27, 3025-3033.

Zhang, Y., Peng, C., Wang, J., Huang, S., Hu, Y., Zhang, J. \& Li, D. (2019). Temperature and silicate are significant driving factors for the seasonal shift of dominant diatoms in a drinking water reservoir. Journal of Oceanology and Limnology, $37(2), 568-579$.

URL-1: https://earthexplorer.usgs.gov [Erișim Tarihi: 01.04.2019]

URL-2: https://corinecbs.tarimorman.gov.tr [Erişim Tarihi: 01.08.2021] 